\title{
THIS IS HOW WE DO IT: GETTING STUDENTS TO READ THE TEXTB00K
}

\author{
Alli Schilling, Grand Canyon University \\ Helen G. Hammond, Grand Canyon University
}

Many of the courses taught at the college level are extremely reading intensive; covering as many as seven chapters over a two-week time span. Reading the textbook in courses such as these is the foundation on which success is built. So, how can instructors get students to read? Faculty teaching in the College of Business at a large private university located in the Southwest United States set out to unpack this mystery and explore ideas to ensure that students have the tools and resources to be successful in class - and to start holding them accountable for their own reading.

\section{THE WHAT AND THE WHY}

The what is the college textbook. The why is because instructors want students to be successful. After all, it's not about the instructor; it's about the students. Yet, research shows that students are reading less (Baier, Hendricks, Warren Gordon, Hendricks, \& Cochran, 2011). So how can instructors engage students with the textbook? This is a question that has challenged instructors for generations, and has led them to actively explore strategies that ignite interest among students to crack open their textbooks (Fleck, Richmond, Rauer, Beckman, \& Lee, 2017).

\section{Reading Is Not A 'Spectator Sport'}

Prior to addressing tips, tricks, and best practices to get students to read, the importance of reading the textbook must first be underscored. Reading enhances the learning of content and serves as the second professor. Reading improves the comprehension of the content (Ryan, 2006). The more an individual reads about a content area, the more they will able be to synthesize and apply that content (Shenkman, 2002). In addition, reading improves vocabulary and writing skill (Heavenridge, 2015). Critical thinking skills are engaged and further developed through reading (Mendenhall \& Johnson, 2010), all of which prepare a student for graduate school and career; not to mention personal development.

\section{Why Students Don't Read}

It's no secret that students do not always complete their weekly reading assignments, and there are plenty of reasons for why that happens. In today's world of fast information, many younger students do not enjoy sitting down to read a traditional textbook. They have too much on their plates between classes, friends, and work. They may not have the time management skills to balance it all. Students also tend to focus on what earns them points in class. Sure, reading helps students reach a higher level of understanding to earn them a better score on assignments or exams, but instructors are not awarding points for simply completing the reading. Finally, they believe that instructors will tell them everything that they need to know. A question often asked by students, "Is there a study guide for the exam?" For most instructors, it is too many times to count!

A study by Baier et al. (2011), found that only $24.8 \%$ of students actually completed the weekly reading before coming to class. Even worse, $18.7 \%$ did not complete the reading at all (Baier et al., 2011). In the same study, they found that a shocking $89.1 \%$ of students surveyed thought they could earn $\mathrm{a} \mathrm{C}$ or better without doing any of the reading (Baier et al., 2011). This information makes it all the more apparent that instructors need to help and motivate students to complete the assigned readings.

\section{How Do You Help?}

How do instructors know where to start in this process? The first step is to make the expectations clear. Starting the class with clear and upfront expectations is always helpful. Do not just tell students that they need to read; tell them why. Have tough exams in class? Make it clear that reading the chapters is the place to start for studying. Let students know that every single aspect of a term or concept may not be discussed in class and that 
exams can cover everything in the texts. Do the same for assignments and discussions.

Communicate those expectations in a way that works for each class. It can be in the syllabus, in acknowledgement posts at the start of class, or in weekly check-ups with students. Make it clear that reading a college level text takes time and effort and that students need to dedicate themselves appropriately. Many instructors have the expectation that students should be citing and referencing the text in discussion forum posts and participation. Make reading expectations clear from the start. Also, if those are the expectations, make sure to model it as well. Cite, reference, and use direct examples from the text to not only model good academic behaviors, but also to encourage students to do the same. However, it is important to avoid using reading as busy work (Baier et al., 2011). Evaluate the readings and focus on what is important and valuable.

\section{THIS IS HOW WE DO IT}

Technology is an awesome tool for learning; that is if online educators choose to continue to stretch and improve how content is provided. Textbooks are provided both electronically and in paper format; however, the challenge remains to get students to actually read them. Instructors in the College of Business at a private Christian University located in the Southwest United States have begun to explore and implement technology in their online and face-to-face classrooms to encourage students to read the textbook. Below, six best practices are described that have proven beneficial to students and inspired them to read.

\section{Three Tips for Success from a Student}

Read the textbook-analyze and apply concepts-use all resources. These were the recommendations from Steven, a university student who just aced his organizational behavior course - a course widely understood among his peers as one of the most challenging in the business program. Steven presented these tips in a brief, three-minute Loom video for online students in which he details exactly how he got that "A."

In another three-minute Loom video clip, Antwon, a student who also recently completed the same course, shared his tips for success in in the same course which he completed on campus. In his video, he highlights tips for success which included being proactive, participate, and attend exam review sessions.

\section{How to Read the Text Like You Mean It}

One way to get students to read the text is to break it down in simple steps. Anderson (2013) suggested a four-step process in her article, "Four Steps to Reading a Textbook Quickly and Effectively." She suggested starting with the questions in the back of the chapter first, then reading the summary, reviewing the headings, and finally reading the introduction (Anderson, 2013). The author also suggested reading for big ideas and then focusing on the details (Anderson, 2013). If done correctly, students should have to read the chapter once, while reading their notes multiple times. This is definitely a new strategy for many students and will certainly take some time to get used to, but it is worth the practice! Anderson (2013) stressed that while this does have an adjustment period, it will save time and ensure that students fully understand each chapter.

Making a video outlining this process with an actual textbook can be incredibly helpful. Walking students through these steps in a Loom video with the textbook on the screen will help them visualize the process and understand how to get started. A short video, focusing on the first chapter works well, as students can try this process right away. Keep it concise and add personalized tips in as well. Make the video once and have it ready to share at the start of each class.

\section{Chapter Lecture Slides}

Get creative! Help students see the connection from the text. Slides should enhance, not replace. Remember the goal here is to drive the student to the textbook to get more information. Recommend that students use the chapter lecture slides and take notes in the notes section while reading the textbook. One best practice would be to create one PowerPoint for each chapter if there are multiple reading assignments per week. This will help the student to break the content into smaller pieces and to be able to easily access each chapter. In addition, it will keep students from getting overwhelmed.

\section{Chapter Highlight Videos}

Often, instructors give students a reading assignment, and then find out after the fact that they haven't read the assigned readings. Students may 
be challenged to stay focused and find it difficult to follow along as they read. To combat this, instructors can create "Chapter Highlight Videos," using a web enhanced video recording such as Loom. These mini-lecture videos can then be easily posted in the course announcements within the Learning Management System (LMS). One benefit of using this type of Web tool, is that the settings can be pre-set so that every time a video is viewed, the faculty member receives a notification.

Each chapter highlight video is approximately 10 minutes in length, and covers a section of the chapter. Generally speaking, it will take anywhere from two to four highlight videos for each chapter in the textbook. When creating the video, it is recommended to start with an overview of what will be covered in the clip. In addition, this is a good time to encourage students to follow along using their textbook, and to take notes either on the slides provided, or in their notebooks. Then the lecture can begin! At the end of the lecture it is important to provide a summary to highlight what was covered.

\section{Knowledge Checks}

Many textbooks offer end-of-the-chapter questions that can be used by students as a temperature check of their mastery of concepts. Provide these as a review resource for students and explain how they can be used to prepare for the exam. One useful approach is to create PowerPoint slides for each question with the question/answer provided in the notes section of the slide. Slides may be reviewed to quiz the student on questions and answers.

Another approach would be to use an online quiz tool such as Kahoot! Questions can be loaded into the online interactive platform to create an interactive quiz that may be reviewed by students. Encourage students to use the textbook initially to find answers that they don't know. Then encourage students to test their understanding without the textbook and track the questions missed. Then reread the sections of the textbook where concepts were missed.

\section{Use the Text}

This is an area in which instructors can really let textbooks shine! There are great aspects of just about every textbook; instructors just need to find them. There are a few ways to get started here, and instructors can determine what works best for students and the content in each course.

Start by finding something interesting that relates to current events or pop culture. Is there a term in a particular week that can be tied to something that students will be excited to talk about? If so, pull it out into a great post or discussion forum topic. Do not give everything away about the term, but rather introduce the term and link it to the textbook. Once students have responded, follow up with another term from the text. Think of it almost like a scavenger hunt. Also, stress that these terms are important to know and understand for future exams and assignments.

Another aspect that can be interesting for students are case studies. These are usually found in most textbooks and can help students better relate concepts to real world situations. Again, the key is to make students actually read the case studies and understand the terms presented. Start with a simple post about the case study, letting students know what page they can find it on. Give a little background, but avoid giving away too much. Remember, the goal is for instructors to get students to actually open the text. Keep the posts interesting, and keep following up as students respond. This is the key! Drive the conversation back to the reading again and again. Instructors can make this more fun by being mindful of their tone and keeping the conversation lighthearted and casual. Update your subject lines in your online conversations to reflect terms and pull students into the conversation.

\section{CONCLUSION}

Reading a college textbook can be overwhelming, scary, and downright awful for some students. Using the suggestions mentioned above can help ease these fears and make the process more learning intensive and interesting for students. While the initial creation and implementation of these resources takes time, most of these resources can be used time and time again, making the instructors job easier and increasing student learning and engagement in class. 


\section{References}

Anderson, S. (2013, March 18). Four steps to reading a college textbook quickly and effectively. Retrieved from https://ecee. colorado.edu/ ecen2250/Resources/ReadingATextbook2.pdf

Baier, K., Hendricks, C., Warren Gorden, K., Hendricks, J. E., \& Cochran, L. (2011). College students' textbook reading, or not! America Reading Forum Annual Yearbook, 31.

Conole, G., Dyke, M., Oliver, M., \& Seale, J. (2004). Mapping pedagogy and tools for effective learning design. Computers \& Education,43, 17-33.

Fleck, B., Richmond, A. S., Rauer, H. M., Beckman, L., \& Lee, A. (2017). Active reading questions as a strategy to support college students' textbook reading. Scholarship of Teaching and Learning in Psychology, 3(3), 220-232. doi:10.1037/ st1000090

Heavenridge, P. (2015). Why read? Reason \#7. The more one reads, the better writer they become. Retrieved from http:// www.literacyworks.org/news/2015/6/2/why-read-reason-7the-more-one-reads-the-better-writer-they-become

Helms, J. W., \& Helms, K. T. (2010). Note launchers: Promoting active reading of mathematics textbooks. Journal of College Reading and Learning, 41(1), 109-119.

Knight, B. A. (2015). Teachers' use of textbooks in the digital age. Cogent Education, 2:1015812.

Mendenhall, A., \& Johnson, T. (2010). Fostering the development of critical thinking skills, and reading comprehension of undergraduates using a Web 2.0 tool coupled with a learning system. Interactive Learning Environments, 18(3), 263-276. doi/abs/10.1080/10494820.2010.500537

Merrill, M. D. (2002) First principles of instruction. Educational Technology Research and Development, 50(3), 1042-1629.

Ryan, T. E. (2006). Motivating novice students to read their textbooks. Journal of Instructional Psychology, 2, 135.

Shenkman, H. (2002). Reading, learning and thinking seminars: A template for faculty training. Learning Abstracts, League for Innovation in the Community College, 5(1).

Yonker, J. E., \& Cummins-Sebree, S. (2009). To read or not to read: How student characteristics relate to textbook reading. AURCO Journal, 15163-172. 